\section{Inverse Knapp procedure}

The article by Maurino, Kwan and Lee ${ }^{1}$ in this issue retrospectively describes the authors' experiences with the relatively uncommon operation of infra-placement of the horizontal recti to the level of the inferior rectus muscle (inverse Knapp procedure). It represents the largest published case series to date and is a valuable addition to the small number of previously published retrospective and longitudinal case series. ${ }^{2-4}$

The inverse Knapp operation is the generally accepted primary procedure of choice for acquired isolated inferior rectus weakness of a marked to severe degree without mechanical restriction. The procedure reduces symptomatic primary position and downgaze vertical deviations, minimises lid malposition, improves compensatory head postures and functionally improves the field of binocular single vision. There is no evidence in the literature to suggest that this desirable effect deteriorates over time. Additional surgery may still be required to lessen residual symptomatic vertical diplopia, since the procedure cannot be expected to normalize downgaze versions in this patient subgroup.

The inverse Knapp procedure is also utilised for congenital absence or palsy of the inferior rectus with variable results. ${ }^{1,5}$ Maurino and colleagues describe another potential use, namely management of patients with symptomatic residual miscellaneous hypertropias and poor binocular functions. ${ }^{1}$ These are a group of patients where the ipsilateral inferior rectus ductions may be normal/near normal and, as such, the inverse Knapp procedure becomes one of a number of surgical options that the ophthalmologist needs to consider.
Partial weakness of the inferior rectus muscle of a mild to modest amount may be best managed by non-transposition procedures using adjustable sutures where appropriate. The benefits of full or graded inverse Knapp procedures in this patient subgroup are less clear-cut, since the risk of symptomatic overcorrections may be increased, although various authors have reported encouraging results with transposition and non-transposition operations. ${ }^{1,6,7}$ For these patients the choice of operation should be individualised after careful evaluation of the extent and the sequelae of the inferior rectus dysfunction.

\section{References}

1. Murino V, Kwan ASL, Lee JP. Review of the inverse Knapp procedure: indications, effectiveness and results. Eye 2001;15:7-11.

2. Lipton JR, Page AB, Lee JP. Management of diplopia on down-gaze following orbital trauma. Eye 1990;4:535-7.

3. Burke JP, Keech RV. Effectiveness of inferior transposition of the horizontal rectus muscles for acquired inferior rectus paresis. J Pediatr Ophthalmol Strabismus 1995;32:172-7.

4. Metz HS. Saccades with limited downward gaze. Arch Ophthalmol 1971;86:451-4.

5. Cooper EL, Greenspan JA. Congenital absence of the inferior rectus muscle. Arch Ophthalmol 1971;86:451-4.

6. von Noorden GK, Hansell RH. Clinical characteristics and treatment of isolated inferior rectus paralysis. Ophthalmology 1991;98:253-7.

7. Denning AM, Ansons AM, Spencer AL, et al. Does the degree of inferior rectus palsy influence the effectiveness of the inverse Knapp procedure? Trans Eur Strabismus Assoc 1997;24:97-102
Mr J. Burke

Department of Ophthalmology and

Orthoptics

O Floor

Royal Hallamshire Hospital

Glossop Road

Sheffield S10 2JF, UK 